\title{
OS EIXOS ESTRUTURANTES DAS DIRETRIZES CURRICULARES NACIONAIS DOS CURSOS DE MEDICINA NO BRASIL
}

\author{
Diogo Hiroshi Beçon Kussakawa ${ }^{1}$ \\ Clésio Acilino Antonio ${ }^{2}$
}

\section{RESUMO}

As reformas curriculares dos cursos de Medicina no Brasil são territórios em disputa por forças com intensidades, direções e sentidos variáveis, emanadas de diversas fontes do conhecimento, em determinado tempo histórico. Tais forças estão organizadas em eixos estruturantes, que orientam a redação dos artigos e parágrafos de projetos pedagógicos e diretrizes. O principal objetivo deste artigo foi identificar, de forma panorâmica, os eixos estruturantes que modelam os currículos dos cursos de Medicina no Brasil e, de forma específica, contextualizá-los com os eventos históricos recentes. Como metodologia, utilizamos os conceitos da pesquisa bibliográfica e documental e, como principal fonte de análise, as novas Diretrizes Curriculares Nacionais dos Cursos de Medicina (DCN), de junho de 2014. Os resultados do trabalho apontam para a presença de quatro grandes eixos: promoção da saúde, político-econômico, ético-cultural e simbólico-tecnológico.

Palavras-chave: Educação médica. Formação médica. Reforma curricular. Diretrizes Curriculares Nacionais.

\footnotetext{
${ }^{1}$ Centro de Ciências da Saúde, Universidade Estadual do Oeste do Paraná, Francisco Beltrão, PR, Brasil.

${ }^{2}$ Centro de Ciências Humanas, Universidade Estadual do Oeste do Paraná, Francisco Beltrão, PR, Brasil.
} 


\title{
THE STRUCTURING AXES OF THE NATIONAL CURRICULAR GUIDELINES OF MEDICINE GRADUATION COURSES IN BRAZIL
}

Diogo Hiroshi Beçon Kussakawa

Clésio Acilino Antonio

\begin{abstract}
The curricular reforms of Medicine graduation courses in Brazil are territories in dispute for forces with variable intensities, directions and senses, emanating from many different knowledge sources, in a specific historical time. These forces are organized in structuring axes, which guide the writing of articles and paragraphs of guidelines and pedagogic projects. The main objective of this paper was to identify, in a panoramic way, the structuring axes that model the curricula of Medicine graduation courses in Brazil and, in a specific way, to contextualize them with recent historical events. As methodology, we used the concepts of bibliographic and documentary research and, as main analysis source, the new National Curricular Guidelines of Medicine Graduation Courses, of June 2014. The results point to the existence of four major axes: health promotion, political-economic, ethical-cultural and symbolic-technological.
\end{abstract}

Keywords: Medical education. Medical training. Curricular reform. National Curricular Guidelines. 


\section{INTRODUÇÃO}

Nos últimos vinte anos, observamos uma aceleração do debate sobre o ensino médico no Brasil, particularmente, sobre a implantação de reformas curriculares para os cursos de Medicina. As Diretrizes Curriculares Nacionais (DCN) de 2001 e 2014 substituíram a rigidez de formas e conteúdos das grades do currículo mínimo, decretado na Lei da Reforma Universitária de 1968, e flexibilizaram a construção dos projetos pedagógicos, ao respeitar a autonomia das instituições de ensino superior e permitir a inovação e a diversificação na formação do profissional.

As DCN são palco de debates e confrontos, no qual há disputa entre forças de diversas áreas do conhecimento: filosóficas, culturais, pedagógicas, econômicas, sociais e políticas, contextualizadas em dado tempo e local. Os objetivos deste artigo foram, panoramicamente, identificar essas forças modeladoras, seus processos de desenvolvimento histórico e como elas estruturaram os textos das diretrizes curriculares dos cursos de Medicina no Brasil; e apontar em que medida elas impactam as propostas de reforma dos processos formativos da graduação em Medicina.

Como metodologia, utilizamos os conceitos da pesquisa bibliográfica e documental, com a análise de conteúdo das DCN 2014 e de artigos e pareceres que as sustentam.

O texto das DCN apresenta um formato alongado e segmentado, porém, nitidamente, percebemos duas partes bem distintas. A primeira contém os aspectos conceituais do perfil formativo do egresso e a segunda, os artigos com força de lei, relacionados aos processos de formação e às práticas pedagógicas. Neste artigo, concentramos nossa investigação apenas na primeira parte.

O trabalho de análise permitiu a descoberta de quatro eixos estruturantes, que correspondem às quatro seções deste artigo. O eixo principal é o de promoção da saúde e trata das determinações sociais do processo de saúde e doença e dos novos conceitos de saúde. No segundo eixo, identificado como político-econômico, esclarecemos as relações entre o mercado de trabalho e o perfil formativo do médico. No eixo ético-cultural, abordamos as questões do pluralismo cultural, da equidade e da comunicação em saúde. No último eixo, simbólico-tecnológico, debatemos a autonomia do profissional de saúde e os interesses de poder escorados na atuação desse profissional. 
Nas seções correspondentes, debateremos o impacto de cada eixo sobre as propostas de reforma dos processos formativos, em especial, sobre a metodologia de "aprendizagem pelo trabalho", que preconiza a inserção precoce do graduando no ambiente real e diversificado de trabalho e consolida a disposição pedagógica atual de primazia da prática sobre a teoria. O ambiente real de trabalho possibilita aos alunos entrar em contato com todos os sujeitos envolvidos no processo de produção de saúde, profissionais e não profissionais, numa interação dialética e interdisciplinar. Há também o fator de incerteza das relações entre os sujeitos, em razão da singularidade dos processos de saúde e doença e da autonomia de cada pessoa frente ao plano terapêutico. Tal metodologia deseja promover alguns conceitos, como a interdisciplinaridade; a diversificação dos cenários de aprendizagem; a importância do contexto social, econômico e ambiental; a autonomia e a comunicação horizontal; e a formação geral e não especializada.

\section{O ESQUELETO AXIAL DAS DCN - PROMOÇÃO DA SAÚDE}

Notamos um eixo estruturante central, presente em todo o percurso das DCN, que influencia os demais em maior ou menor intensidade. Esse eixo torna-se central porque define a principal característica do perfil formativo do graduado em Medicina, a finalidade dessa formação. O eixo em evidência é o de promoção da saúde, talhado pelos conceitos atuais de saúde e de saúde coletiva. Esses conceitos reconheceram a saúde não apenas como uma condição orgânica dos indivíduos, mas construída por determinações sociais ${ }^{3}$.

O artigo 3 das DCN 2014, definidor atual do perfil formativo, demonstra, de forma clara, a importância das determinações sociais e a necessidade de as diretrizes estarem presentes, de forma transversal, em toda a prática médica, seja em promoção seja em prevenção, recuperação e reabilitação da saúde:

Art. 3ㅇ 0 graduado em Medicina terá formação geral, humanista, crítica, reflexiva e ética, com capacidade para atuar nos diferentes níveis de atenção à saúde, com ações de promoção, prevenção, recuperação e reabilitação da saúde, nos âmbitos individual e coletivo, com responsabilidade social e compromisso com a defesa da cidadania, da dignidade humana, da saúde integral do ser humano e

\footnotetext{
${ }^{3}$ Determinações sociais da saúde são características socioeconômicas, culturais e ambientais de uma sociedade que influenciam as condições de vida e o trabalho de todos os integrantes.
} 
tendo como transversalidade em sua prática, sempre, a determinação social do processo de saúde e doença (BRASIL, 2014, p. 1, grifo nosso).

A Promoção da Saúde é definida "como o processo que permite às pessoas adquirir maior controle sobre sua própria saúde, sobre os determinantes da saúde e, ao mesmo tempo, melhorá-la" (PELICIONI, M.; PELICIONI, A.; TOLEDO, 2008, p. 165). A definição aparenta ser simples, mas é repleta de significados. Podemos entendê-la como a capacitação do indivíduo para buscar a qualidade de vida, com a saúde não mais como finalidade, mas como recurso aplicável à vida cotidiana; com a identificação, a compreensão e o controle dos fatores favoráveis ou prejudiciais ao bem-estar próprio e ao da comunidade; e, dessa maneira, minimizar o risco e a vulnerabilidade ao adoecimento e garantir a melhoria das condições de vida da população. O conceito carrega em si o desafio de alcançar o objetivo pela necessidade do envolvimento de múltiplos setores da sociedade e do estado, como: educação, justiça social, políticas públicas, economia, suporte ambiental etc.

Os rudimentos do conceito de Promoção da Saúde remontam ao século XIX, relacionados a antigas preocupações do movimento sanitário europeu com as questões ambientais, como as epidemias por doenças infectocontagiosas nos recém-estabelecidos aglomerados urbanos. No Brasil, o movimento chegou ao auge no início do século XX e foi liderado pelo ideário sanitarista e campanhista de Oswaldo Cruz, no combate à gripe espanhola, à peste bubônica, à varíola e à febre amarela, com a utilização de conhecimentos sobre as causas das doenças e ações de prevenção (TEIXEIRA, 2012).

Em contraposição ao sanitarismo, desde o início do século XX e com consolidação na década de 1930, deu-se a tecnologização da medicina, com a descoberta dos micro-organismos e o desenvolvimento dos medicamentos e exames complementares. A preocupação voltou-se para a cura dos indivíduos manifestantes de alterações fisiopatológicas. O desenvolvimento tecnológico delimitou a saúde como estado de ausência de doença e inaugurou uma nova era na medicina, a era terapêutica, apoiada nos princípios naturalistas e reducionistas do positivismo. $\mathrm{Na}$ atenção à saúde, o indivíduo foi reduzido ao aspecto biológico, fragmentado em órgãos e sistemas, o que impulsionou a especialização do médico e a medicina curativa. Na educação em saúde, "o conhecimento das especialidades se localizou na divisão das disciplinas, agrupadas em básicas e profissionalizantes, fragmentando a unidade do conhecimento médico, ainda no curso de graduação" (LAMPERT, 2001, p. 8). O ensino encontrava-se centrado no professor especialista, baseado no empirismo das pesquisas científicas, encastelado no interior dos 
hospitais e desarticulado das determinações sociais. Santos e Westphal (1999) descrevem com propriedade esse período:

\begin{abstract}
Com os progressos médicos alcançados no ensino, na pesquisa e na prática foi se consolidando o paradigma, até hoje vigente. O principal elemento desse referencial é o curativismo e, entre os demais elementos, o mecanicismo (tal como acontece na mecânica clássica, uma causa atuando num corpo, sempre produz um efeito. Incorporase aqui a noção de unicausalidade: é uma causa, produzindo um efeito); o biologicismo (as doenças e suas curas sempre ocorrem no nível biológico); o individualismo (o objeto das ações em saúde é um indivíduo, tratado por outro indivíduo, excluindo-se portanto dessa ação o contexto ambiental, o social e o histórico); e a especialização. O curativismo, como referido, é o elemento primordial, pois, como a saúde é a ausência da doença num indivíduo, o diagnóstico e a terapêutica ganham toda a relevância no processo. Assim, a prática sanitária passa a ser a busca da cura dos indivíduos que manifestaram alguma doença (SANTOS; WESTPHAL, 1999, p. 73, grifo dos autores).
\end{abstract}

O declínio dessa concepção começou no período pós-guerra imediato, em 1947, quando a Comissão Interina da Organização Mundial da Saúde definiu a saúde como um estado de completo bem-estar físico, mental e social, e não apenas a ausência de enfermidade. Em 1948, a Assembleia Geral das Nações Unidas proclamou a Declaração Universal dos Direitos Humanos e assegurou a saúde, entre outros direitos, como fundamental e garantida. Houve a ampliação do conceito, com o acréscimo dos determinantes sociais aos aspectos biológicos no binômio saúde e doença, e a inauguração de uma discussão aprofundada sobre o assunto. Na década de 1970, a maioria dos países passou por uma crise no setor da saúde, devido a altos custos da tecnologização e a pesquisas comprovando que os gastos não se refletiam em qualidade de vida para a população. Em 1974, Marc Lalonde, então ministro da Saúde e Bem-Estar do Canadá, questionou o papel exclusivo da medicina na resolução dos problemas, ao publicar o relatório intitulado Novas perspectivas de saúde dos canadenses, e iniciou uma nova era de interesse social e político pela saúde pública. O relatório propôs que as causas de doença e morte estariam relacionadas às características biofísicas dos indivíduos, ao estilo de vida ou ao comportamento, à poluição e agravos ambientais e à inadequação e à incompetência dos serviços de saúde (LALONDE, 1974).

No Brasil, a afirmação dessa nova perspectiva foi legitimada em sucessivas e destacadas políticas públicas. Em 1988, promulgou-se a Constituição Federal Brasileira e a consolidação da saúde como "direito de todos e dever do Estado, garantido mediante políticas sociais 
e econômicas que visem à redução do risco de doença e de outros agravos e ao acesso universal e igualitário às ações e aos serviços para sua promoção, proteção e recuperação" (BRASIL, 1988). Em 1990, articulada com a Constituição Federal, a Lei Orgânica da Saúde criou o Sistema Único de Saúde (SUS), com os seguintes princípios: universalidade, todas as pessoas têm direito ao atendimento, independentemente de cor, raça, religião, local de moradia, situação de emprego ou renda; equidade, todo cidadão é igual perante o SUS e será atendido conforme as necessidades que apresentar; integralidade, as ações de saúde devem ser combinadas e voltadas, ao mesmo tempo, para promoção, prevenção e recuperação da saúde do indivíduo ou de uma comunidade; regionalização, a organização será de forma regionalizada e hierarquizada, voltada para os problemas de saúde de uma população de uma área delimitada; resolutividade, o serviço de saúde deve estar capacitado para enfrentar e resolver problemas de impacto individual e coletivo; descentralização, haverá a redistribuição das responsabilidades entre os vários níveis de governo; e participação do cidadão, a garantia constitucional da população de participar do processo de formulação das políticas de saúde e do controle social com as suas entidades representativas (ZIONI, 2008).

Aderida à Promoção da Saúde está a definição de Saúde Coletiva. Narvai e São Pedro (2008) afirmam que, no plano coletivo, o processo de saúde e doença é considerado como a "expressão de um processo social mais amplo que resulta de uma complexa trama de fatores e relações, representadas por determinantes mais próximos e mais distantes do fenômeno" (NARVAl; SÃO PEDRO, 2008, p. 271). Deixa de ser a soma das condições orgânicas de cada indivíduo e ultrapassa os indicadores quantitativos, ao considerar os aspectos e dimensões qualitativas das situações de saúde e doença. A prática sanitária da Saúde Coletiva volta-se à vigilância à saúde, entendida como aquela que "não incide apenas nos produtos finais dos processos - mortes, sequelas, enfermidades e agravos - mas também nos assintomáticos suspeitas, expostos, grupos de risco e necessidades sociais de saúde" (SANTOS, J., 1999, p. 78). Para além de uma noção simplificadora de Saúde Coletiva, Nunes (2006) conduz uma extensa investigação sobre a natureza plural do conceito. Demonstra o processo histórico de construção da definição de Saúde Coletiva e aponta para uma infinitude de disciplinas e saberes que a influenciam, tais como as ciências sociais e humanas, a epidemiologia e a política e o planejamento: as ciências sociais e humanas, ao auxiliarem na compreensão de processos da vida, como o trabalho, a doença, a morte, os cuidados com os pacientes e as relações profissionais; a epidemiologia, aliada à demografia e à geografia, ao incluir os aspectos ambientais na investigação das causas dos fenômenos de saúde e doença; a política e o planejamento, ao aprofundarem o debate sobre a necessidade de uma racionalização na 
organização e nas escolhas das prioridades dentre as várias possibilidades de satisfação das necessidades de saúde da população.

Distinguimos nos textos das DCN 2014 uma destacada importância dada à Saúde Coletiva no perfil formativo do profissional médico. O termo está presente em diversas seções, paralelas às subseções das necessidades individuais e congruentes com os demais eixos estruturantes. Apesar do consenso dos relatores sobre a relevância da Saúde Coletiva na formação do médico, duras críticas partem da comunidade de educadores médicos à carga de responsabilidades imposta aos novos graduados pelas DCN 2014, devido à natureza polissêmica e à composição de conteúdos com alta diversidade epistemológica do conceito de Saúde Coletiva. Tais autores defendem que creditar ao médico o poder de moldar o sistema de saúde é quase culpá-lo pelas mazelas atuais desse sistema e sugerem uma divisão mais clara entre os papéis do médico e do sanitarista (BURSZTYN, 2015; KLOETZEL, 1986).

Observamos, como no perfil formativo, a forte influência do eixo de promoção da saúde sobre a concepção de "aprendizagem pelo trabalho", na orientação para a diversificação dos cenários de aprendizagem, ao apontar para a complexidade dos problemas de saúde, que exigem, além do conhecimento dos contextos social, econômico e ambiental, a mobilização de vários saberes e ciências para um planejamento terapêutico e preventivo dos agravos.

Síntese de múltiplas determinações, o conceito de Promoção da Saúde constitui-se no núcleo estruturante das DCN 2014. Todos os artigos e parágrafos remetem, direta ou indiretamente, aos fundamentos desse conceito. Cabe entendermos, agora, como outras forças de origens política, econômica, filosófica, cultural, simbólica e tecnológica o complementam.

\section{EIXO POLÍTICO-ECONÔMICO}

Como vimos na seção anterior, a ampliação dos direitos sociais reivindicados após a metade do século XX e consolidados pela Constituição Federal de 1988 estendeu o acesso da população aos serviços de saúde. Como primeira consequência, a imposição de garantir atendimento com financiamento estatal a todos os estratos sociais despertou a necessidade de contratação de profissionais de saúde para atuar na nova fronteira econômica. No campo do mercado de trabalho, de uma profissão liberal e autônoma, o médico apresentou-se, pela primeira vez, ao trabalho assalariado. A escassez de profissionais gerou uma segunda consequência, a expansão do número de escolas médicas, sobretudo as privadas, que, além de capacitar 
os profissionais, precisavam "produzi-los" em quantidade suficiente para suprir um mercado emergente e cada vez maior. O movimento de multiplicação das escolas médicas e de expansão do número de médicos pôde ser observado ao longo de vários períodos da história brasileira: na década de 1960, nos anos finais do governo Fernando Henrique Cardoso e durante todo o período da gestão de Luiz Inácio Lula da Silva. Recentemente, em 2013, o governo Dilma Rousseff instituiu o programa Mais Médicos, com o objetivo de formar recursos humanos na área médica e diminuir a carência de atendimentos em regiões menos desenvolvidas. Somamse a esses fatores as crises cíclicas do capitalismo, como a crise global de 2008; as recentes crises políticas relacionadas a esquemas de corrupção; e a transição epidemiológica, com o envelhecimento da população e o impacto na previdência social. Todas provocaram dúvidas sobre a viabilidade do financiamento dos sistemas de saúde e o achatamento dos recursos destinados ao setor.

Diante desse cenário, três influências de origem econômica são percebidas nos textos das DCN. A primeira é o conceito de produção de saúde, que abriga, sob a definição, a extensão das práticas médicas na estrutura capitalista; a segunda relaciona-se com as competências que os trabalhadores em saúde necessitam para a gestão do processo de produção; e a terceira é a preponderância exigida, pelo mercado de trabalho, do aprendizado prático sobre o teórico. As influências pretendem responder a três questionamentos: qual o papel do médico no mercado de trabalho, de que saberes ele necessita para atuar e de que maneira transmitir tais saberes.

Marx (2008) define a produção como um conjunto de relações sociais construídas pelo homem e o produto como um bem, uma mercadoria, produzida pelo trabalho de agentes, distribuída para a sociedade e consumida pela sociedade. Nessa perspectiva, o médico torna-se operário da produção de saúde; ocupa-se das atividades de promoção, prevenção, recuperação e reabilitação; produz o bem-estar individual e coletivo, distribuído para a sociedade, pela mediação de direitos adquiridos, e consumido pela sociedade, cujas necessidades precisam ser atendidas. Além disso, ao definirmos a saúde como um produto de relações sociais e ao inserirmos a prática médica na estrutura capitalista, apontamos para o papel da medicina na reprodução das condições econômicas e político-ideológicas da sociedade. Uma constatação da afirmação da especificidade da medicina como prática social é a produtividade do trabalho do sistema capitalista. Como produtor de saúde, o médico tem responsabilidade pela manutenção dos níveis de produtividade e de disponibilidade de força de trabalho, tanto no interior do processo produtivo quanto fora dele. No interior do processo produtivo, responsabiliza-se pelos níveis de produtividade, pois "a melhoria das condições de saúde do 
trabalhador possibilita a obtenção de um máximo de produtos em menor tempo de trabalho e, correspondentemente, a produção de mercadorias por custo mais reduzido" (DONNANGELO; PEREIRA, 1976, p. 35). Fora do processo produtivo, o médico tem responsabilidade pela disponibilidade da força de trabalho, ao conservá-la em níveis controlados para a manutenção da produção.

A segunda influência econômica sobre as DCN relaciona-se à aprendizagem pelo trabalho, baseada na abordagem dialógica das competências. Nessa perspectiva construtivista de ensino, a construção de significados pressupõe a transferência da aprendizagem baseada nos conteúdos para uma aprendizagem baseada na integração entre teoria e prática. A reflexão teórica sobre a ação da prática profissional, realizada em situações reais do trabalho, constrói e desenvolve capacidades no indivíduo e permite a manifestação de um estilo próprio, adequado e eficaz, para enfrentar situações profissionais familiares ou não familiares (LIMA, 2005).

Influenciados pelas crises financeiras do setor saúde, percebemos a preocupação dos relatores do parecer ${ }^{4}$ sobre as DCN 2014 com a gestão do processo produtivo, ao definir as competências do trabalho médico, ou seja, os meios de trabalho com os quais os médicos atuarão sobre a matéria-prima, os indivíduos e a comunidade (BRASIL, 2014). Jargões próprios do sistema fabril são observados nos textos das DCN, como: custo e efetividade, retroalimentação, conhecimentos gerenciais, padrão de qualidade e segurança, priorização de problemas, uso apropriado da força de trabalho, interprofissionalidade etc. Além dessas competências mais objetivas, somam-se outras subjetivas, também relacionadas ao mundo do trabalho, como: comprometimento, responsabilidade, empatia, criatividade, autonomia, desenvolvimento do pensamento divergente e da capacidade de comunicação. No processo produtivo, o médico precisa ser operário e gerente, capaz de produzir saúde de maneira eficaz, segura e de qualidade; trabalhar e liderar equipes; considerar custos e benefícios; priorizar as demandas mais urgentes; aprender de forma continuada com as dificuldades enfrentadas e com os resultados obtidos e criar soluções para os problemas com os recursos disponíveis.

A predominância da prática sobre a teoria como elemento central no processo de aprendizagem é a terceira influência evidente da economia política sobre as DCN. As iniciativas são as de inserção precoce do graduando no mercado de trabalho e a de diversificar os

\footnotetext{
${ }^{4}$ Parecer homologado. Despacho do Ministro, publicado no D.O.U. de 6/6/2014, Seção 1, p. 17.
} 
cenários de aprendizagem em diferentes tipos de complexidade e autonomia. Além disso, há a preocupação advinda das constatações de que a maior parte dos recém-formados inicia e afirma as carreiras em unidades de atenção básica, urgência e emergência e de que as formações técnicas e emocionais que possuem para o desempenho dessas funções são insuficientes (PEREIRA, 2015).

O debate sobre a relação entre teoria e prática nas metodologias de ensino não é novo, tampouco envolve apenas a questão econômica, mas a ontológica e a epistemológica. Chauí (2008), no livro O que é ideologia, explica a concepção positivista da relação entre teoria e prática, na qual a primeira deve preponderar sobre a segunda:

1) define a teoria de tal modo que a reduz à simples organização sistemática e hierárquica de ideias, sem jamais fazer da teoria a tentativa de explicação e de interpretação dos fenômenos naturais e humanos a partir de sua origem real. [...]

2) estabelece entre a teoria e a prática uma relação autoritária de mando e de obediência, isto é, a teoria manda porque possui as ideias, e a prática obedece porque é ignorante. Os teóricos comandam e os demais se submetem;

3) concebe a prática como simples instrumento ou como mera técnica que aplica automaticamente regras, normas e princípios vindos da teoria. A prática não é ação propriamente dita, pois não inventa, não cria, não introduz situações novas que suscitem o esforço do pensamento para compreendê-las. (CHAUÍ, 2008, p. 30-31).

Quando as DCN se posicionam favoráveis a uma predominância da prática sobre a teoria, além de reconhecerem a importância da inserção precoce do graduando nas situações reais de trabalho como metodologia de ensino e aprendizagem, buscam consolidar a ruptura com os princípios positivistas que permearam o modelo formativo anterior do ensino médico. 0 eixo político-econômico ainda influencia a metodologia de "aprendizagem pelo trabalho", ao exaltar algumas categorias do processo de trabalho, como a cooperação interdisciplinar, aquela na qual todos os sujeitos, profissionais ou não profissionais da saúde, relacionam-se em consonância, com vistas à produção de saúde; e a educação interdisciplinar, na qual todos os sujeitos aprendem uns com os outros, ampliando o conhecimento sobre as instâncias do processo produtivo e superando as formas de trabalho fragmentadas e alienadas. 


\title{
EIXO ÉTICO-CULTURAL
}

A ampliação dos direitos sociais, proporcionada pela Declaração Universal dos Direitos Humanos, amplificou a força e a voz de grupos identitários por direitos privados, incorporou e extrapolou a dimensão socioeconômica das lutas de classes sociais e inaugurou o embate na esfera da dimensão cultural, como as lutas pelos direitos da mulher, das crianças, dos idosos, dos negros, da comunidade LGBT $^{5}$ etc. Todas essas reivindicações estiveram presentes em todo o século XX, intensificaram-se nas décadas de 1960 e 1970 e chegaram aos dias atuais. Novas identificações e comunidades são constituídas todos os dias e, com elas, as demandas por direitos.

Nas DCN 2014, Seção I - Da Atenção à Saúde, no artigo 5o e no parágrafo I, observamos:

\begin{abstract}
Art. 5o - Na Atenção à Saúde, o graduando será formado para considerar sempre as dimensões da diversidade biológica, subjetiva, étnico-racial, de gênero, orientação sexual, socioeconômica, política, ambiental, cultural, ética e demais aspectos que compõem o espectro da diversidade humana que singularizam cada pessoa ou cada grupo social, no sentido de concretizar:

1 -acesso universal e equidade como direito à cidadania, sem privilégios nem preconceitos de qualquer espécie, tratando as desigualdades com equidade e atendendo as necessidades pessoais específicas, segundo as prioridades definidas pela vulnerabilidade e pelo risco à saúde e à vida, observado o que determina o Sistema Único de Saúde (SUS) (BRASIL, 2014, p. 1-2, grifo nosso).
\end{abstract}

Se a ética é, dentre as muitas definições a ela dadas, a maneira que encontramos para conviver em harmonia; se, para convivermos de forma harmônica, são necessárias conceituações, valorações e escolhas que devem levar em consideração a presença e o reconhecimento do outro como portador de direitos, estabelecidos por códigos elaborados por instituições justas; se estão inscritos na definição de ética um compromisso com a verdade e um dever social; e se o mundo contemporâneo é globalizado e pluricultural, justifica-se a presença desse eixo no corpo das DCN para estruturar a convivência harmoniosa entre o médico e os diversos grupos culturais. O princípio ético e cultural fundamental na formação dos profissionais de saúde é o de equidade, e o instrumento para execução desse princípio, a comunicação. A Lei Orgânica da Saúde de 1990, que instituiu a criação do SUS, tem a equidade como princípio

${ }^{5}$ LGBT é o acrônimo de Lésbicas, Gays, Bissexuais, Travestis, Transexuais e Transgêneros. 
doutrinário. Todo cidadão é igual perante o SUS e será atendido conforme as necessidades que apresentar. O médico e os serviços de saúde devem considerar que existem grupos da população diferentes entre si e que cada grupo tem problemas específicos e modos próprios de viver, de adoecer e de satisfazer as próprias necessidades (ZIONI; ALMEIDA, 2008). A equidade admite que existam desigualdades (socioeconômicas, religiosas, de gênero), mas não admite a iniquidade, o atendimento diferenciado, por parte dos profissionais de saúde, a essas populações.

Na extensão da definição de equidade está o conceito de vulnerabilidade. A vulnerabilidade confunde-se, nos princípios, com a equidade. A confusão está na coincidência, em alguns recortes populacionais adotados, entre grupos culturais e populações de risco. Um exemplo é o aumento das taxas de incidência e mortalidade por dengue em certos grupos de baixa renda. Admite-se que tais grupos existem, mas nem todos se enquadram nos critérios de vulnerabilidade, pois a categorização depende de múltiplas características da população estudada. Para classificarmos pessoas de baixa renda como vulneráveis à dengue, é preciso estudar, além das questões socioeconômicas, o ambiente em que vivem, os cuidados preventivos, as práticas de higiene, o acesso ao atendimento etc. (ADORNO; VASCONCELOS; ALVARENGA, 2008).

Nas DCN 2014, Seção I - Da Atenção à Saúde, no artigo 5o e no parágrafo VII, observamos:

\footnotetext{
VII - comunicação, por meio de linguagem verbal e não verbal, com usuários, familiares, comunidades e membros das equipes profissionais, com empatia, sensibilidade e interesse, preservando a confidencialidade, a compreensão, a autonomia e a segurança da pessoa sob cuidado (BRASIL, 2014, p. 2).
}

Para instrumentalizar o princípio da equidade, está a comunicação em saúde. Comunicar-se bem exige linguagem clara, objetiva e deve conter significados comuns ao profissional de saúde e qualquer indivíduo. A comunicação cria um círculo virtuoso: para o médico, quando permite que relações de confiança sejam estabelecidas e contribuam para identificar causas, fazer diagnósticos precisos e discutir as soluções que se enquadrem ao estilo de vida da pessoa; para o paciente, quando permite a compreensão do problema que enfrenta, das causas e consequências do prognóstico e da conduta a ser seguida, apoiada na segurança. A comunicação ideal é definida como horizontal e compartilhada, pois dispensa a verticalidade das imposições de diagnóstico e tratamento e promove a inclusão do paciente no processo de prevenção, recuperação e reabilitação da saúde. Ganha com isso a promoção da saúde, pois 
apenas com a compreensão e a reflexão dos fatos e com a tomada de decisões conscientes é que as pessoas mudarão os comportamentos frente à presença da doença e para a manutenção da saúde.

A horizontalidade e o compartilhamento podem ser observados, ao longo das DCN 2014, em outro conceito, o de interdisciplinaridade, em substituição ao termo multidisciplinaridade, presente nas DCN 2001. A diferença é semântica. No trabalho em equipe multidisciplinar, as ações de promoção da saúde são realizadas por diversos profissionais, sobre o mesmo indivíduo ou comunidade, de maneiras simultâneas, porém justapostas, desarticuladas entre si. No interdisciplinar, há uma expansão do conceito. Desde o planejamento das ações, a execução e o aprendizado obtido pela equipe são compartilhados entre todos os profissionais envolvidos, em uma relação de reciprocidade.

O eixo ético-cultural impacta a metodologia de "aprendizagem pelo trabalho" ao propor que o médico deve estar formado para entender as desigualdades e tratá-las com equidade, contemplar as necessidades pessoais específicas, mas priorizar os grupos vulneráveis. Deve comunicar-se com todos os grupos culturais e com a equipe interdisciplinar de maneira horizontal e compartilhada, sempre com a promoção da saúde como maior objetivo. A cooperação e a educação interdisciplinar permitirão, como vimos no eixo político-econômico, uma superação da alienação no processo produtivo da saúde.

\section{EIXO SIMBÓLICO-TECNOLÓGICO}

O eixo simbólico-tecnológico não é facilmente detectável nas DCN, oculta-se nas entrelinhas de alguns artigos e parágrafos. Bourdieu $(1989$, p. 7) descreve o poder simbólico como "esse poder invisível o qual só pode ser exercido com a cumplicidade daqueles que não querem saber que lhe estão sujeitos ou mesmo que o exercem". Não se trata da ingenuidade do currículo oculto, ou seja, aquelas suposições em sala de aula que não são planejadas, pelo próprio fato de serem tácitas e incidentais; trata-se de informações dispostas de maneira deliberada e que, por estarem circunscritas por outros princípios e conceitos, passam despercebidas. Para exemplificar, nas DCN 2014, Seção II - Da Gestão em Saúde, artigo 6ㅇ, parágrafo IV, observamos:

IV - Comunicação, incorporando, sempre que possível, as novas tecnologias da informação e comunicação (TICs), para interação a 
distância e acesso a bases remotas de dados (BRASIL, 2014, p. 3, grifo nosso).

As palavras sempre que possível, citadas no parágrafo IV, do artigo 6을 das DCN 2014, permitem a interpretação de alguma cautela ou discordância, por parte dos relatores, diante da inclusão de tema tão contraditório: o controle simbólico.

O controle social pelo currículo remonta ao século XVII, quando influenciada pelas ideias do calvinismo e da teoria da predestinação, a minoria abastada e predestinada à salvação era agraciada com a perspectiva de uma escolarização avançada (GOODSON, 1995). Desde então, muitos autores nos alertaram para o embasamento de diversas teorias de construção dos sistemas de ensino em que o controle e a diferenciação sociais estão presentes nos currículos: de fundo econômico, ideológico e cultural (BOURDIEU; PASSERON, 1970; APPLE, 1982; FORQUIN, 1993). No quarto final do século XX, com a popularização do computador e da internet e a consequente massificação desses recursos, houve uma clara percepção de mudanças na sociedade, proporcionadas pelo desenvolvimento científico e tecnológico, sobretudo na área da informática. A observação otimista dessas mudanças aponta que estão nelas a resolução das desigualdades de riqueza e conhecimento por meio da democratização da informação; a pessimista acredita que as mudanças têm criado novos mecanismos de exclusão social e controle. Por um lado, as novas tecnologias da informação expandiram o campo da distribuição de conhecimentos, sobretudo na geração e no processamento, por outro, limitaram os processos de inovação científica e tecnológica, aumentaram o nível de abstração da produção e levaram a um fortalecimento do vínculo entre o trabalho e o controle simbólico, de forma pacífica e inquestionável (SANTOS, L., 1999).

O grande princípio discutido nesse tópico é a autonomia do profissional de saúde. Sem dúvida, mantendo-se a coerência com o foco dado à Saúde Coletiva em todo o texto das DCN 2014, as redes de informação, a interação a distância e as bases remotas de dados são úteis no planejamento das estratégias de promoção da saúde, na distribuição de recursos e na geração e no processamento de protocolos diagnósticos e terapêuticos. No entanto, o controle proporcionado por essas tecnologias diminui a autonomia do médico, ao enrijecer as opções nas tomadas de decisão, limitar o pensamento crítico e científico e impedir a inovação. Um exemplo é a confecção e a distribuição de algoritmos de tratamento de doenças, que analisam informações de diagnóstico e classificam os indivíduos em grupos, nos quais serão ofertadas soluções estanques de tratamento. Quando uma falha ocorre, o erro não estará no algoritmo, 
mas no interpretador da classificação. Há uma sutil, mas perceptível incoerência entre o controle simbólico e o discurso de liberdade crítica propagado de forma ampla nas DCN.

Nas DCN 2014, Seção II - Da Gestão em Saúde, artigo 6, parágrafo II, encontramos:

II - Valorização da Vida, com a abordagem dos problemas de saúde recorrentes na atenção básica, na urgência e na emergência, na promoção da saúde e na prevenção de riscos e danos, visando ’̀ melhoria dos indicadores de qualidade de vida, de morbidade e de mortalidade, por um profissional médico generalista, propositivo e resolutivo (BRASIL, 2014, grifo nosso).

Há uma grande preocupação, por parte dos agentes políticos, com os índices epidemiológicos de saúde. O prestígio interno é impactado pelos índices, e observamos, em várias ocasiões, nos discursos e campanhas eleitorais, quantas foram as melhoras. Não são raras as vezes em que observamos as políticas públicas serem motivadas pelo descontentamento da população, como na ocasião da instituição do Programa Mais Médicos, de 2013, em resposta a manifestações populares. Na área internacional, as políticas públicas em saúde do Brasil são vigiadas por instituições externas relacionadas à área, como a Organização Pan-Americana de Saúde (OPAS) e a Organização Mundial de Saúde (OMS), mas, também, por instituições externas relacionadas ao campo econômico, como o Fundo Monetário Internacional (FMI), a Organização para a Cooperação e o Desenvolvimento Econômico (OCDE) e o Banco Mundial. Goodson (2008) relata que as mudanças nos sistemas de saúde e educacional, impulsionadas pelas relações externas, passam por quatro fases: a formulação da mudança nas arenas externas; a promoção da mudança, definida e transmitida por grupos externos com vários graus de envolvimento interno; a legislação da mudança, promulgada por esforços políticos dos países envolvidos; e o estabelecimento da mudança, a legitimação das leis nos países. Passa pelo cumprimento das metas, o prestígio internacional, político e econômico, relevante para credibilidade, atratividade a investimentos externos e capacidade de endividamento dos países em desenvolvimento (RIZZOTTO, 2000).

No contexto apresentado, o impacto do eixo simbólico-tecnológico sobre a capacitação profissional do médico envolve propósitos embutidos nas DCN, disfarçados entre os artigos, com a pretensão deliberada de controle, seja no cerceamento da autonomia do profissional de saúde seja com o objetivo de melhoria de indicadores de qualidade de vida, morbidade e mortalidade da população. 


\section{CONSIDERAÇÕES FINAIS}

A primeira pergunta a ser feita diante da tarefa de construir ou reformar um currículo é "que perfil de profissional queremos formar?", e a resposta, como vimos, não é fácil, tampouco objetiva. As forças de modelação aplicadas sobre a constituição das diretrizes e dos currículos são infinitas, com intensidades, direções e sentidos variáveis, delimitadas no tempo e no espaço. Algumas têm grande capacidade de deformação e são capazes de criar rupturas, grandes transformações de forma e de conteúdo. Outras, surgem e desaparecem, como se não tivessem existido. Ora são esporádicas e débeis, originárias de movimentos do interior do sistema educacional, incapazes de romper a barreira que as circundam, ora são forças externas, carregadas de força simbólica, emanadas de diversas fontes, promovidas por diferentes agentes. Por vezes, os tensionamentos têm uma direção e um sentido; em outras, têm uma mesma direção, mas sentido contrário; e, ainda, em outras vezes, evidenciam-se direções e sentidos diferentes.

As Diretrizes Curriculares Nacionais dos cursos de graduação em Medicina são palco de atuação dessas forças, que as constroem e modelam, dinamicamente. Os eixos estruturantes apontam a direção e o sentido que se quer dar ao ensino da medicina no país, rumo a um novo paradigma educacional, comprometido com uma resposta às necessidades em saúde da população, motivadas pelas condições históricas concretas. Legisladores, gestores, professores e alunos observam e participam do movimento de formação e deformação do novo paradigma, em maior ou menor intensidade, na disputa pela definição da melhor proposta educacional e, consequentemente, da melhor proposta para a saúde de todos.

\section{REFERÊNCIAS}

ADORNO, R. C. F.; VASCONCELlOS, M. P.; ALVARENGA, A. T. Saúde Pública, Ciências Sociais e as chamadas populações vulneráveis. In: ROCHA, A. A.; CESAR, C. L. G. (Org.). Saúde Pública: bases conceituais. São Paulo: Atheneu, 2008, p. 297-310.

APPLE, M. W. Ideologia e currículo. São Paulo: Brasiliense, 1982.

BOURDIEU, P. O poder simbólico. Trad. Fernando Tomaz. Rio de Janeiro: Bertrand Brasil, 1989. 
BOURDIEU, P.; PASSERON, J. C. A reprodução: elementos para uma teoria do sistema de ensino. Petrópolis, RJ: Vozes, 1970.

BRASIL. Constituição (1988). Constituição da República Federativa do Brasil, 1988. Brasília: Senado Federal, 1988.

BRASIL. Diretrizes Curriculares Nacionais do Curso de Medicina. Conselho Nacional de Educação. Câmara de Educação Superior. Resolução no 3, de 20 de junho de 2014.

BURSZTYN, I. Diretrizes Curriculares Nacionais de 2014: um novo lugar para a saúde coletiva?. In: Cadernos da ABEM: Novas Diretrizes Curriculares Nacionais para a Medicina: avanços e desafios, v. 11, p. 7-19, 2015.

CHAUÍ, M. O que é ideologia. São Paulo: Brasiliense, 1994.

DONNANGELO, M. C. F.; PEREIRA, L. Saúde e sociedade. São Paulo: Duas Cidades, 1976.

FORQUIN, J. C. As implicações educativas do pluralismo cultural. In: FORQUIN, J. Escola e cultura: as bases sociais e epistemológicas do conhecimento escolar. Porto Alegre: Artes Médicas, 1993, p. 123-143.

GOODSON, I. F. Currículo: teoria e história. Petrópolis, RJ: Vozes, 1995, p. 29-43.

GOODSON, I. F. Processos de mudança e períodos históricos: uma perspectiva internacional. In: GOODSON, I. F. As políticas de currículo e escolarização: abordagens históricas. Trad. Vera Joscelyne. Petrópolis, RJ: Vozes, 2008, p. 59-72.

KLOETZEL, K. Saúde: atacado ou varejo. Revista Brasileira de Educação Médica, v. 10, n. 3, p. 182-184, 1986.

LALONDE, M. A new perspective on the health of canadians: a working document. Ottawa: Government of Canada, 1974.

LAMPERT, J. B. Currículo de graduação e o contexto da formação do médico. Revista Brasileira de Educação Médica, v. 25, n. 1, p. 7-19, 2001.

LIMA, V. V. Competência: distintas abordagens e implicações na formação de profissionais de saúde. Interface - Comunic., Saúde, Educ., v. 9, n. 17, p. 369-79, mar./ago. 2005.

MARX, K. Contribuição à crítica da economia política. São Paulo: Expressão Popular, 2008. 
NARVAI, P. C.; SÃO PEDRO, P. F. Práticas de saúde pública. In: ROCHA, A. A.; CESAR, C. L. G. (Org.). Saúde Pública: bases conceituais. São Paulo: Atheneu, 2008, p. 269-295.

NUNES, E. D. Saúde coletiva: história recente, passado antigo. In: CAMPOS, G. W. S.; MINAYO, M. C. S.; AKERMAN, M.; DRUMOND JÚNIOR, M.; CARVALHO, Y. M. (Org.). Tratado de saúde coletiva. Rio de Janeiro: Fiocruz, 2006, p. 19-39.

PELICIONI, M. C. F.; PELICIONI, A. F.; TOLEDO, R. F. A educação e a comunicação para a promoção da saúde. In: ROCHA, A. A.; CESAR, C. L. G. (Org.). Saúde Pública: bases conceituais. São Paulo: Atheneu, 2008, p. 165-177.

PEREIRA JR., G. A. et al. O ensino de urgência e emergência de acordo com as novas Diretrizes Curriculares Nacionais e a Lei do Mais Médicos. In: Cadernos da ABEM: Novas Diretrizes Curriculares Nacionais para a Medicina: avanços e desafios, v. 11, p. 20-45, 2015.

RIZZOTTO, M. L. F. O Banco Mundial e as políticas de saúde no Brasil nos anos 90: um projeto de desmonte do SUS. Tese (Doutorado em Saúde Coletiva) - Faculdade de Ciências Médicas, Universidade Estadual de Campinas, Campinas, 2000.

SANTOS, J. L. F.; WESTPHAL, M. F. Práticas emergentes de um novo paradigma de saúde: 0 papel da universidade. Estudos Avançados, São Paulo, v. 13, n. 5, p. 71-88, 1999.

SANTOS, L. L. C. P. Saberes escolares e o mundo do trabalho. In: FERRETTI, C. J.; SILVA JUNIOR, J. R.; SALES, M. R. N. (Org.). Trabalho, formação e currículo: para onde vai a escola? São Paulo: Xamã, 1999, p. 63-74.

TEIXEIRA, L. A.; EDLER, F. C. História e cultura da medicina no Brasil. São Paulo: Aori, 2012.

ZIONI, F.; ALMEIDA, E. S. Políticas públicas e sistemas de saúde: a Reforma Sanitária e o SUS. In: ROCHA, A. A.; CESAR, C. L. G. (Org.). Saúde Pública: bases conceituais. São Paulo: Atheneu, 2008, p. 103-118.

\section{Diogo Hiroshi Beçon Kussakawa}

Professor da Universidade Estadual do Oeste do Paraná (UNIOESTE), campus de Francisco Beltrão. Docente do curso de Medicina. Mestrando em Educação pela Universidade Estadual do Oeste do Paraná (UNIOESTE), campus Francisco Beltrão.

diogo.kussakawa@gmail.com 


\section{Clésio Acilino Antonio}

Doutor em Educação pela Universidade Federal do Rio Grande do Sul (UFRGS) e mestre em Educação pela Universidade Federal de Santa Catarina. Professor adjunto da Universidade Estadual do Oeste do Paraná (UNIOESTE), campus de Francisco Beltrão. Docente do curso de Pedagogia e do Programa de Pós-graduação em Educação - Mestrado em Educação.

clesioaa@hotmail.com 